\title{
Association between Black Stains and Dental Caries in Primary Teeth: Findings from a Brazilian Population-Based Birth Cohort
}

\author{
C.C. França-Pinto ${ }^{a}$ M.S. Cenci ${ }^{a} \quad$ M.B. Correa ${ }^{a}$ A.R. Romano ${ }^{a}$ M.A. Peres ${ }^{c}$ \\ K.G. Peres ${ }^{c}$ A. Matijasevich ${ }^{b} \quad$ I.S. Santos ${ }^{b}$ A.J.D. Barros ${ }^{b}$ F.F. Demarco ${ }^{a, b}$ \\ a Postgraduate Program in Dentistry and b Postgraduate Program in Epidemiology, Federal University of Pelotas, \\ Pelotas, and ' Postgraduate Program in Public Health, University of Santa Catarina, Florianópolis, Brazil
}

\section{Key Words}

Black stains $\cdot$ Child $\cdot$ Cohort studies $\cdot$ Dental caries $\cdot$ Oral health

\begin{abstract}
Lower dental caries experience has been observed in children and teenagers with the presence of black stains on dental structures. However, none of the previous investigations were population-based studies or adjusted the analysis for potential confounders. This study assessed the prevalence of black stains at the age of 5 in a population-based birth cohort from Pelotas, Brazil and investigated the association between black stains and dental caries. A total of 1,129 children from the 2004 Pelotas birth cohort were examined at age 5, and their mothers were interviewed at their households. Dental examinations included a search for black stains and dental caries on the primary dentition through the dmf-s index. The mothers' questionnaire comprised data on demographic, social, and behavior aspects. Prevalence of black stains was 3.5\% (95\% Cl 2.5-4.7) and the prevalence of dental caries was $48.4 \%$ (95\% Cl 45.4-51.4). Multivariable logistic regression analysis was performed to assess the association between black stains and dental caries. Adjusted analysis revealed that the presence of black stains was asso-
\end{abstract}

ciated with lower levels of dental caries (OR $=0.51 ; 95 \% \mathrm{Cl}$ $0.26-0.99)$. The results of the present study suggest that black stains are a protective factor for dental caries development.

Copyright $\odot 2012$ S. Karger AG, Basel

Even though dental caries has experienced a significant decrease worldwide, it remains one of the most prevalent childhood diseases, especially in low and middle income countries [Sheiham, 2005]. In Brazil, despite the improvement over the last decades, dental caries is the most important oral health problem, and it is considered a public health concern [Antunes et al., 2005]. Furthermore, by age $5,43.4 \%$ of Brazilian children have caries [Ministry of Health, 2011], with $82 \%$ of carious teeth occurring in $12 \%$ of the children [Ferreira et al., 2007]. Dental caries is strongly associated with the lack of fluoride availability, socioeconomic factors such as low maternal education and low family income, and behavioral and cultural factors such as poor oral hygiene and poor dietary habits (frequent consumption of refined carbohydrates, frequent use of oral medications that contain sugar, and inappropriate methods of feeding infants) [Fejerskov, 2004; Kiwanuka et al., 2004; Antunes et al., 2005;

\section{KARGER}

Fax +4161306 1234

E-Mail karger@karger.ch

www.karger.com
(C) 2012 S. Karger AG, Basel

$0008-6568 / 12 / 0462-0170 \$ 38.00 / 0$

Accessible online at:

www.karger.com/cre
Flávio Fernando Demarco

Universidade Federal de Pelotas, Faculdade de Odontologia

Rua Gonçalves Chaves $457,5^{\circ}$ andar - Centro

96015568 Pelotas, RS (Brazil)

Tel. +55 533222 6690, E-Mail flavio.demarco@ pq.cnpq.br 
Ferreira et al., 2007; Selwitz et al., 2007; Declerck et al., 2008]. Therefore, the investigation of potential caries protective factors, especially in the most affected population, is an essential key to reduce dental caries inequalities.

Extrinsic dark dental pigmentation was associated with lower levels of caries in a school population in the Philippines [Heinrich-Weltzien et al., 2009]. Studies in Brazil have also demonstrated this relationship in mixed dentition [Gasparetto et al., 2003; Caldas et al., 2008]. Black extrinsic stains of bacterial origin are formed by ferric sulfide, which is a by-product of the reaction between hydrogen sulfide produced by bacteria and the iron ions present in saliva and gingival exudates [Reid et al., 1977]. These black stains are present as dots or small areas of dark coloration that may coalesce, forming a line that follows the contour of the marginal gingiva. They may also appear as diffuse stains, covering a great part of the tooth crown. The grooves, pits, and fissures can also be found to be impregnated with such pigmentation, which is difficult to remove, particularly in these areas [Koch et al., 2001]. We are unaware of any population-based study that investigated the prevalence of black stains; however, in non-population-based studies, the prevalence of black stains varies from 2.5 to $19 \%$. This variation depends on factors such as study region, age of population enrolled, and dietary habits [Gülzow, 1963; Franco and Issao, 1990; Koch et al., 2001; Caldas et al., 2008; Heinrich-Weltzien et al., 2009].

Up to now, few studies have addressed the prevalence of black stains in deciduous teeth, and none has controlled for confounding variables [Koch et al., 2001; Gasparetto et al., 2003; Gallardo and Cencillo, 2005; Heinrich-Weltzien et al., 2009]. This study assessed the prevalence of black stains in the primary dentition of a birth cohort of 5-year-olds from Pelotas, RS, Brazil. We also tested the hypothesis that the presence of black stains is associated with lower levels of dental caries after adjusting for potential confounders.

\section{Methods}

In $2004,4,558$ children were born in the urban area of Pelotas, Southern Brazil. Of the 4,231 live births, 99\% were evaluated within the first $24 \mathrm{~h}$ after birth, $96 \%$ at 3 months of age, and $94 \%$ at 12 months of age. Details about the methodology of the cohort study have already been published [Barros et al., 2006].

This work is part of a comprehensive oral health study $(\mathrm{OH}-$ 04) nested in the Pelotas 2004 birth cohort, carried out in 2009. The mothers of all of the 5-year-old children born between August and December $2004(\mathrm{n}=1,303)$ were invited to participate. The sample size is sufficient to test associations with a power of at least $80 \%$ to detect significant relative risks of 2 or more, signifi- cant at type I error of 5\%, considering a prevalence of outcomes of $5 \%$ in nonexposed children.

Mothers were interviewed with the help of a structured questionnaire, and children underwent an oral examination; both the interview and the examination were performed at their homes. Black stains are defined as two neighboring teeth presenting black dots parallel to the gingival margin or covering up to one third of the crown with difficult removal [Theilade et al., 1973; Koch et al., 2001]. Dental examinations also included the investigation of dental caries on the primary dentition through the dmfs index [World Health Organization, 1997], which was later dichotomized using two cut points: $\mathrm{dmfs} \geq 1$ (presence of one or more caries lesions) and $\mathrm{dmfs} \geq 3$.

The characteristics of the mothers, such as family income and educational level, were collected at the hospital soon after the children's birth. Family income at birth was collected in Brazilian currency Reais (BRL; 1 USD = 1.7 BRL) and then categorized into quartiles. Maternal education at childbirth was categorized into four groups: $\leq 4,5-8,9-11$, and $\geq 12$ completed years of study.

Mothers were asked 'What kind of water does your child drink?' Water type was categorized as tap, mineral bottled, well, or other. Frequency of consumption of sweet foods or drinks was obtained by asking 'How many times a day does your child eat sweets between meals? For example: candies, cookies, lollipops, gum, chocolates?' and 'How many times a day does your child have sweetened drinks?' Answer choices were 'never or less than once a day'; 'once a day'; 'twice a day', and ' 3 times or more per day'.

Eight dentists, students from the masters or PhD courses in dentistry at the Federal University of Pelotas, were trained and calibrated according to a method described elsewhere [Peres et al., 2001]. The calibration process was conducted with 100 preschool children at the age of the surveyed children. These children were not included in the study sample. Interexaminer diagnostic reproducibility was assessed by kappa coefficient (categorical variables) and by the intraclass correlation coefficient (continuous and discrete variables). High reproducibility was observed for dental caries ( $\mathrm{dmfs}$ ); the intraclass coefficient varied between 0.9 and 1.0 and kappa varied between 0.85 and 1.0 for first molars. For black stains, the lowest value for kappa was 0.6 and the highest 1.0.

For the fieldwork, the dentists, each assisted by a dental undergraduate student, conducted the interviews first and followed with the dental examinations to ensure that the questionnaire responses were not influenced by examination outcome. Children were examined sitting under artificial illumination (head lamp). The examiners were properly dressed, and all safety and biohazard measures were adopted. Furthermore, in order to assess data quality, $15 \%$ of the interviews were repeated with a shortened version of the questionnaire by fieldwork supervisors by telephone. The kappa for the evaluated questions varied between 0.6 and 1.0 .

The process of data entry occurred simultaneously with the fieldwork. Data were double-typed using Epi-Info 6.04, and the consistency of information was subsequently verified. For data analysis, STATA software version 10 was used. Descriptive analysis was performed to describe absolute and relative frequencies and to calculate the prevalence of black stains and dental caries. The associations between black stains and the presence of dental caries with independent variables were assessed using bivariate 
Table 1. Association between independent variables and black stains in children aged 5 in Pelotas, Brazil (bivariate analysis, $\mathrm{n}=$ $1,120)$

\begin{tabular}{|c|c|c|c|}
\hline \multirow[t]{2}{*}{ Variable/category } & \multicolumn{2}{|c|}{ Black stains, $\mathrm{n}(\%)$} & \multirow{2}{*}{$\begin{array}{l}\mathrm{p} \\
\text { value }\end{array}$} \\
\hline & no & yes & \\
\hline Total sample & $1,081(96.5)$ & $39(3.5)$ & \\
\hline Sex & & & $0.069^{*}$ \\
\hline Male & $560(95.6)$ & $26(4.4)$ & \\
\hline Female & $520(97.6)$ & $13(2.4)$ & \\
\hline Family income at birth & & & $0.036^{*}$ \\
\hline 1st quartile & $266(94.7)$ & $15(5.3)$ & \\
\hline 2nd quartile & $273(95.5)$ & $13(4.6)$ & \\
\hline 3rd quartile & $307(97.5)$ & $8(2.5)$ & \\
\hline 4th quartile & $235(98.7)$ & $3(1.3)$ & \\
\hline Mother's educational level & rth, years & & $0.014^{*}$ \\
\hline$\leq 4$ & $135(93.8)$ & $9(6.3)$ & \\
\hline $5-8$ & $418(95.2)$ & $21(5.0)$ & \\
\hline $9-11$ & $383(98.0)$ & $8(2.1)$ & \\
\hline$\geq 12$ & $122(99.2)$ & $1(0.8)$ & \\
\hline Water origin & & & $0.007^{*}$ \\
\hline Tap/filtered & $798(95.6)$ & $37(4.4)$ & \\
\hline Mineral & $266(99.3)$ & $2(0.8)$ & \\
\hline Wells/other & $15(100.0)$ & $0(0.0)$ & \\
\hline Sweet consumption & & & $0.567^{*}$ \\
\hline Less than once a day & $321(97.6)$ & $8(2.4)$ & \\
\hline Once a day & $318(96.4)$ & $12(3.6)$ & \\
\hline Twice a day & $224(96.1)$ & $9(3.9)$ & \\
\hline Three times or more & $212(95.5)$ & $10(4.5)$ & \\
\hline Sweet drinks consumption & & & $0.085^{*}$ \\
\hline Less than once a day & $329(95.9)$ & $14(4.1)$ & \\
\hline Once a day & $198(96.1)$ & $8(3.9)$ & \\
\hline Twice a day & $176(99.4)$ & $1(0.6)$ & \\
\hline Three times or more & $377(95.9)$ & $16(4.1)$ & \\
\hline
\end{tabular}

* Fisher's exact test.
Table 2. Association between independent variables and dental caries in children aged 5 in Pelotas, Brazil (bivariate analysis, $\mathrm{n}=$ $1,120)$

\begin{tabular}{|c|c|c|c|}
\hline \multirow[t]{2}{*}{ Variable/category } & \multicolumn{2}{|c|}{ Dental caries, n (\%) } & \multirow{2}{*}{$\begin{array}{l}\mathrm{p} \\
\text { value }\end{array}$} \\
\hline & no & yes & \\
\hline Total sample & $578(51.65)$ & $542(48.35)$ & \\
\hline Sex & & & $0.043^{*}$ \\
\hline Male & $287(48.81)$ & $301(51.19)$ & \\
\hline Female & $293(54.87)$ & $241(45.13)$ & \\
\hline Family income at birth & & & $<0.001^{* *}$ \\
\hline 1st quartile & $114(40.43)$ & $168(39.57)$ & \\
\hline 2nd quartile & $131(45.80)$ & $155(54.20)$ & \\
\hline 3rd quartile & $179(56.47)$ & $138(43.53)$ & \\
\hline 4th quartile & $156(65.55)$ & $82(34.45)$ & \\
\hline \multicolumn{3}{|c|}{ Mother's educational level at birth, years } & $<0.001^{* *}$ \\
\hline$\leq 4$ & $57(39.58)$ & $87(60.42)$ & \\
\hline $5-8$ & $198(44.90)$ & $243(55.10)$ & \\
\hline $9-11$ & $222(56.63)$ & $170(43.37)$ & \\
\hline$\geq 12$ & $84(68.29)$ & $39(31.71)$ & \\
\hline \multicolumn{3}{|l|}{ Water origin } & $0.002^{*}$ \\
\hline Tap/filtered & $412(49.16)$ & $426(50.84)$ & \\
\hline Mineral & $162(60.45)$ & $106(39.55)$ & \\
\hline Wells/other & $5(33.33)$ & $10(66.67)$ & \\
\hline \multicolumn{3}{|l|}{ Sweet consumption } & $<0.001^{* *}$ \\
\hline Less than once a day & $180(54.38)$ & $151(45.62)$ & \\
\hline Once a day & $197(59.70)$ & $133(40.30)$ & \\
\hline Twice a day & $123(52.79)$ & $110(47.21)$ & \\
\hline Three times or more & $78(34.98)$ & $145(65.02)$ & \\
\hline \multicolumn{3}{|c|}{ Sweet drinks consumption } & $<0.001^{* *}$ \\
\hline Less than once a day & $185(53.78)$ & $159(46.22)$ & \\
\hline Once a day & $129(62.62)$ & $77(37.38)$ & \\
\hline Twice a day & $99(55.93)$ & $78(44.07)$ & \\
\hline Three times or more & $167(42.28)$ & $228(57.72)$ & \\
\hline \multicolumn{3}{|l|}{ Black stains } & $0.349^{*}$ \\
\hline No & $555(51.34)$ & $526(48.66)$ & \\
\hline Yes & $23(58.97)$ & $16(41.03)$ & \\
\hline
\end{tabular}

analysis ( $\chi^{2}$ and Fisher's exact test for categorical variables and $\chi^{2}$ for linear trend for ordinal variables). Logistic regression models were used to analyze the presence of black stains as a protective factor for dental caries with two cut points of the disease, adjusting for potential confounders.

All variables that presented a $\mathrm{p}$ value $\leq 0.25$ in the bivariate analysis were included in the multivariable analysis to control for possible confounding factors. Variables were organized in levels to guide their entrance in the statistical analysis. The demographic variable gender was placed at the first level as a distal determinant. Socioeconomic variables (familial income and maternal education) were grouped at the second level, followed by behavioral variables at the third level (i.e., sugar consumption). As black stains were associated in bivariate analysis with the same independent variables that showed association with the presence of dental caries, this variable was kept in the final model as a proximal determinant, although showing a $p$ value greater than 0.25 .
The project was approved by the Ethics Committee of the Federal University of Pelotas under number 100/2009 on 29/06/2009. All examinations and interviews were carried out after authorization by the parent of the participant through a consent letter. Children who had dental needs were referred to the Pedodontics Dental Clinic, Dental School, Federal University of Pelotas.

\section{Results}

The response rate was $86.6 \%(n=1,129)$. However, data on the prevalence of black stains were collected from 1,120 children because 9 children refused to be exam- 
Table 3. Association between the prevalence of dental caries and black stains in children aged 5 in Pelotas, Brazil (logistic regression analysis, $\mathrm{n}=1,120)$



Model 1: adjusted by gender; model 2: adjusted by model $1+$ maternal education + family income; model 3: adjusted by model $2+$ sweet consumption frequency (candies and drinks); model 4: final model (model 3) with $\mathrm{dmfs} \geq 3$ as the outcome.

p value of Hosmer-Lemeshow test: model $3=0.834$; model $4=0.557$. Pseudo R2: model $3=0.060 ;$ model $4=0.07$.

ined. Black stains were observed in 39 children $(3.5 \%$; 95\% CI 2.5-4.7), and the caries prevalence was $48.4 \%$ (45.4-51.4). The mean dmfs indexes for children with or without black stains were 3.3 (SD 6.7) and 4.1 (SD 7.4), respectively. Although no statistical difference was observed in bivariate analysis, caries-free children showed higher prevalence of black stains $(4.0 \% ; 3.0-5.3)$ than those with $\mathrm{dmfs}>0(3.0 \% ; 2.0-4.1)$.

Factors associated with black stains are shown in table 1. Black stains were more prevalent in children with mothers of low education level, and in children with lower family income at birth. Furthermore, children who drank tap water had more black stains than those who drank mineral bottled water, natural well water, or other.

Unadjusted analysis showed that caries was more prevalent in males, in children whose mothers had less education, and in children whose mothers had lower family income at the children's birth. Furthermore, children who drank water from natural wells presented higher caries prevalence than those who drank mineral water or tap/filtered water. Children who consumed sweets or sweetened drinks 3 or more times per day showed a higher prevalence of caries (table 2).

Adjusted logistic regression analysis revealed an association between black stains and dental caries for both cut points used ( $\mathrm{dmfs} \geq 1$ or $\mathrm{dmfs} \geq 3$; table 3 ). Children with black stains showed a reduction of $51 \%$ in the odds for dental caries prevalence. After adjustment for confounding factors, black stains presented an OR $=0.49$ (95\% CI $0.25-0.96)$. Under the cut point $\mathrm{dmfs} \geq 3$, a stronger association in the same direction was observed $(0.41 ; 0.19$ $0.87)$. 


\section{Discussion}

This was the first study to investigate the presence of black stains and their potential protective effect on dental caries considering an adjustment for demographic, social, and behavioral factors that influence both dental caries and black stains. Additionally, this study is a pioneer in showing the prevalence and the association of black stains with dental caries in a population-based study. The present study was carried out in a birth cohort that was followed since 2004 [Barros et al., 2006], which makes this investigation less susceptible to information bias. The internal validity of the study is a consequence of the high reproducibility of examiners and a low amount of missing data.

Even though the children surveyed are enrolled in a birth cohort, this was the first time that they underwent dental examination. Consequently, the present study showed a limitation with respect to establishing a temporal relationship between black stains and dental caries. In addition, the use of dmfs index was elected to the detriment of a more sensitive tool such as ICDAS. The choice for $\mathrm{dmfs}$ was due to the facility of use in large epidemiologic studies, with many oral outcomes to be evaluated and children with lower age. In addition, multivariable final models used two cut points for dental caries occurrence, conferring strength to our findings. The sample of this study was calculated based on an at least $5 \%$ prevalence of the outcomes to test associated factors. Despite this fact, we found a significant association between black stains and several variables.

The very low prevalence of black stains (3.48\%) observed in this study agrees with findings from non-population-based studies carried out in Brazil, that found a prevalence ranging between 2.5 and 5.7\% [Franco and Issao, 1990; Caldas et al., 2008]. However, the prevalence may vary, depending on where the study is conducted, from 19\% in Switzerland [Gülzow, 1963] to 6.3\% in Italy [Koch et al., 2001] and more recently, 16\% in the Philippines [Heinrich-Weltzien et al., 2009]. The variability in the prevalence observed in the different studies could be attributed to differences in habits and lifestyles of the specific populations investigated. The etiology of black stains is not yet completely understood, so it is possible that different cultural and ethnic aspects can affect the origin of black stains. Additionally, some variation in the diagnostic criteria of black stains is expected among different studies, which may also affect prevalence data.

It is well known that socioeconomic characteristics such as maternal education and family income are deter- minant factors for caries [Selwitz et al., 2007; Meurman and Pienihäkkinen, 2010]. This association is supported by the results of the current study. In addition, we found a significant association between the presence of black stains and some of these determinants, with children from families with lower incomes and those with mothers with less education showing a higher prevalence of these stains. This association is interesting because at the same time, the presence of black stains and higher prevalence of decayed teeth were observed in the lower socioeconomic levels.

Regarding the association of dental caries and black stains, although no association was found between these variables in one study [Gallardo and Cencillo, 2005], other studies agree with our findings, demonstrating lower caries experience for children with black stains [Shourie, 1947; Sutcliffe, 1967; Koch et al., 2001; Heinrich-Weltzien et al., 2009]. Gasparetto et al. [2003] showed a negative correlation between black stains and caries severity, but did not find any association between the presence of black stains and caries prevalence. Similarly, Koch et al. [2001] found a tendency for children with black stains in primary dentition to present less dental caries, but the difference was not statistically significant. However, the mechanisms that lead to this association need further exploration.

The present findings showed that both black stains and dental caries had common co-variables, such as socioeconomic and behavioral characteristics. Considering these results and taking into account that we observed caries reduction in children presenting black stains in their teeth, it is reasonable to hypothesize that the independent variables tested in our investigation would behave as positive confounding factors. Similarly, Duckworth and Huntington [2005] investigated the inverse association between dental calculus and dental caries explaining that some studies did not find a relationship between these variables because, as dental caries and black stains, they were correlated positively with other variables such as poor oral hygiene. Similarly to dental calculus formation [Duckworth and Huntington, 2005], calcium and phosphate are part of the reaction for black stain formation [Reid and Beeley, 1976] and together with fluoride and $\mathrm{pH}$ conditions are the main tooth remineralization components. Because caries development is a demineralization process due to the acids produced by oral bacteria, the presence of a larger amount of minerals in the oral cavity - which could be the case in children with black stains - enhances the remineralization process, keeping the oral cavity in a balanced equilibrium 
and reducing the risk for caries development [Gasparetto et al., 2003].

Other hypotheses require further investigation. Firstly, the low caries prevalence is a result of particular characteristics such as traditional dietary habits (sustainable community structures, limited exchange of goods and food, and limited exposure to a Western lifestyle) that were reported by Heinrich-Weltzien et al. [2009] as a possible cause of black stains. In the current study, sweets consumption was not associated with black stains. Nevertheless, this variable depends on the recall by children's mothers, which is susceptible to information bias, being a limitation of this study.

Secondly, it has been reported that low cariogenic oral microflora is associated with the presence of black stains [Theilade et al., 1973; Saba et al., 2006], and this could be a reason for the reduction of caries prevalence in individuals with dental black stains. It is noteworthy that bacteria related to black stains could establish a competitive environment for bacteria related to caries development, impairing the adhesion of these bacteria to dental surfaces or changing the ecological characteristics of the dental biofilm, somewhat reducing the potential for caries lesion development. This phenomenon can be observed mainly in people of low socioeconomic status because the wealthier segment of the population has easier access to bacterial accumulation prevention by dental service utilization and better feeding/hygiene habits. This explains how socioeconomic factors affect both dental caries and black stain prevalence. However, these hypotheses remain to be tested.

In conclusion, our findings highlight the need to use a statistical approach with multivariable analysis in future studies related to the prevalence of black tooth stains and its association with dental caries. In the clinical setting, the results of this study suggest that clinicians may consider the inclusion of black stains as a protective indicator when assessing caries risk in children. The results of this study support the notion that black stains are associated with lower levels of caries. Although this study demonstrated a relatively low prevalence of these stains in children at age 5, the significant association merits further investigation regarding the biological aspects of this caries inhibition mechanism.

\section{Acknowledgments}

This article is based on data from the study 'Pelotas Birth Cohort, 2004' conducted by the Postgraduate Program in Epidemiology at the Federal University of Pelotas.

The 2004 Birth Cohort Study is currently supported by the Wellcome Trust Initiative entitled Major Awards for Latin America on Health Consequences of Population Change. Previous phases of the study were supported by the World Health Organization, National Support Program for Centers of Excellence (PRONEX), the Brazilian National Research Council (CNPq), the Brazilian Ministry of Health, and the Children's Mission.

This oral health study was sponsored by the Brazilian government agency CNPq with a grant to KGP (402372/2008-5). Also, the authors would like to thank the Brazilian government agency CAPES for the scholarship to the first author.

\section{Disclosure Statement}

The authors of the present study declare that there are no conflicts of interests in relation to this study.

\section{References}

Antunes JL, Jahn GM, de Camargo MA: Increasing inequalities in the distribution of dental caries in the Brazilian context in Finland. Community Dent Health 2005;22:94-100.

Barros AJD, Santos IS, Victora CG, Albernáz EP, Domingues MR, Timm IK, Matijasevich A, Bertoldi AD, Barros FC: Birth cohort from Pelotas, 2004: methodology and description (in Portuguese). Rev Saude Pública 2006;40: 402-413.

Caldas CT, Mialhe FL, Silva RP: Prevalence of extrinsic black dental stains and its relation to dental caries in the municipality of Santa Terezinha de Itaipu - PR (in Portuguese). Rev Fac Odontol UPF 2008;13:22-26.
Declerck D, Leroy R, Martens L, Lesaffre, E, Garcia-Zattera M-J, Vanden Broucke S, Debyser M, Hoppenbrouwers K: Factors associated with prevalence and severity of caries experience in preschool children. Community Dent Oral Epidemiol 2008;36:168-178.

Duckworth RM, Huntington E: Evidence for putting the calculus:caries inverse relationship to work. Community Dent Oral Epide miol 2005;33:349-356.

Fejerskov O: Changing paradigms in concepts on dental caries: consequences for ora health care. Caries Res 2004;38:182-191.
Ferreira SH, Béria JU, Kramer PF, Feldens EG, Feldens CA: Dental caries in 0- to 5-year-old Brazilian children: prevalence, severity, and associated factors. Int J Paediatr Dent 2007; 17:289-296.

Franco KD, Issao M: Black stains and their relationship to dental caries (in Portuguese). Rev Paul Odontol 1990;12:23-30.

Gallardo VP, Cencillo CP: Chromogenic staining: a common problem in pediatric clinic (in Spanish). An Pediatr 2005;62:258-260.

- Gasparetto A, Conrado CA, Maciel SM, Miyamoto EY, Chicarelli M, Zanata RL: Prevalence of black tooth stains and dental caries in Brazilian school children. Braz Dent J 2003;14:157-161. 
Gülzow HJ: Schwarze und grüne Zahnbeläge: Untersuchungen über ihre Häufigkeit und über ihre Beziehung zur Kariesfrequenz. Dtsch Zahnärztl Z 1963;18:1370-1376.

-Heinrich-Weltzien R, Monse B, Helderman WP: Black stain and dental caries in Filipino schoolchildren. Community Dent Oral Epidemiol 2009;37:182-187.

-Kiwanuka SN, Astrøm AN, Trovik TA: Dental caries experience and its relationship to social and behavioural factors among 3-5-yearold children in Uganda. Int J Paediatr Dent 2004;14:336-346.

Koch MJ, Bove M, Schroff J, Perlea P, GarcİaGodoy F, Staehle HJ: Black stain and dental caries in schoolchildren in Potenza, Italy. J Dent Child 2001;68:353-355.

Meurman PK, Pienihäkkinen K: Factors associated with caries increment: a longitudinal study from 18 months to 5 years of age. Caries Res 2010;44:519-524.
Ministério da Saúde, SAS/SVS/Departamento de Atenção Básica:. Coordenação Nacional de Saúde Bucal. Pesquisa Nacional de Saúde Bucal 2010. Resultados Principais. Brasília, Ministério da Saúde, 2011.

Peres MA, Traebert JL, Marcenes W: Calibration of examiners for dental caries epidemiologic studies. Cad Saude Publica 2001;17:153-159.

Reid JS, Beeley JA: Biochemical studies on the composition of gingival debris from children with black extrinsic tooth stain. Caries Res 1976;10:363-369.

Reid JS, Beeley JA, MacDonald DG: Investigations Into black extrinsic tooth stain. J Dent Res 1977;56:895-899.
- Saba C, Solidana M, Berlutti F, Vestri A, Ottolenghi L, Polimeni A: Black stains in the mixed dentition: a PCR microbiological study to the etiopathogenic bacteria. J Clin Pediatr Dent 2006;30:219-224.

Selwitz RH, Ismail AI, Pitts NB: Dental caries. Lancet 2007;369:515-519.

Sheiham A: Oral health, general health and quality of life. Bull World Health Organ 2005;83: 544-545.

Shourie KL: Mesenteric line or pigmented: a sign of comparative freedom from caries. J Am Dent Assoc 1947;35:805-807.

Sutcliffe P: Extrinsic tooth stains in children. Dent Pract 1967;17:175-179.

Theilade J, Slots J, Fejerskov O: The ultrastructure of black stain on human primary teeth. Scand J Dent Res 1973;81:528-532.

World Health Organization: Oral Health Survey: Basic Methods, ed 4. Geneva, WHO, 1997. 